\title{
Early Motherhood at the Hospital of Gecamines Kipushi: Prognosis and Profile of the Newborn
}

\author{
Ngoie Mwana Nsapu Adelard, Ngomb Kazad Aline, Mwinkeu Kasongo Narcisse \\ Lubumbashi Nursing College, Lubumbashi, Democratic Republic of Congo \\ Email: narcissemk@yahoo.fr
}

How to cite this paper: Adelard, N.M.N. Aline, N.K. and Narcisse, M.K. (2018) Early Motherhood at the Hospital of Gecamines Kipushi: Prognosis and Profile of the Newborn. Open Access Library Journal, 5: e4356.

https://doi.org/10.4236/oalib.1104356

Received: January 12, 2018

Accepted: March 4, 2018

Published: March 7, 2018

Copyright $\odot 2018$ by authors and Open Access Library Inc.

This work is licensed under the Creative Commons Attribution International License (CC BY 4.0).

http://creativecommons.org/licenses/by/4.0/

\begin{abstract}
The present transversal descriptive survey aims to determine the prognosis, the frequency and seeks to describe the profile of the newborn babies from the early motherhood. It was conducted on 66 new babies from 60 mothers. Early motherhood concerned the single young ladies at $65 \%$. They developed urogenital infections at $38.3 \%$. Their socio-economic conditions were unfavorable at $68.3 \%$. Concerning vital prognosis of the newborn children, from early motherhood, they noticed neonatal mortality estimated at $7.6 \%$.
\end{abstract}

\section{Subject Areas}

Public Health

Keywords

Early Motherhood, Prognosis, Profile, Newborn

\section{Introduction}

If the consequences of the early pregnancy seem relatively well known, it is not the case with its factors of occurrence. Throughout the developed and developing countries, teenage pregnancy is more prevalent among disadvantaged youth during their childhood and who have a week expectation as far as educational and job opportunities. Documentation proves that young people who are living in poverty have a teenage pregnancy rate five times higher than the average [1].

Thus social and economic factors seem to play a major role in teen pregnancy rates. The children of teen parents are more likely to encounter problems and to become also parents at teenage, thus perpetuating the cycle of poverty that began through the birth of a baby of teenage mother [2].

Due to its impact on infant morbidity and mortality, as well as its implications 
on health in adulthood, low birth weight constitutes a major public health problem in the Democratic Republic of Congo. As a result of the difficult social and economic conditions, young girls contract unprotected sexual intercourses and the occurrence of the pregnancy forces them in some cases to start the life of a couple without any preparation or to have benefited from prenatal care that can prevent the risks of maternal and neonatal death.

The mining city of Kipushi, being an urban and rural city, also records cases of early marriage justified by the social and cultural environment in which the young girl prefers marriage to studies.

This work is meant to contribute to the re-education of the neonatal mortality after describing the profile of mothers who experienced early childbearing. In addition, this work aims at determining the frequency of early maternity and the foeto-maternal prognosis.

\section{Material and Method}

The present transversal descriptive investigation was conducted for approximately five months and two weeks, from $1^{\text {st }}$ April to $15^{\text {th }}$ September 2016. The investigation population consisted of 66 newborn babies from 60 mothers less than 18 years of age.

In our survey we have included:

- All the teenager mothers of less than 18 years of age and their newborn babies have been registered during the period of survey.

- All the mothers having more than child and aged of more than 18 years.

The data were gathered by the means of a scale containing the following variables: age of the mothers, marital status, socio and economic conditions, the profession of the partner, pregnancy complications, type of pregnancy, gestation age, early delivery risks, the vital prognosis of the mothers and of the newborn babies, the APGAR at the first minute, the causes of neonatal and maternal death.

The mining city of Kipushi is urban and rural and is located at about 30 kilometers from the city of Lubumbashi in southern region of D. R. Congo (on the border with Zambia).

The data collected on the pot were encoded thanks to Epi info3.5.4 software (2012) and the results obtained were presented in the tables.

After obtaining free consent and enlightened the mothers, we have classified the participants in two social and economic categories. Social and economic conditions were favorable for any person having a stable employment with a regular and reasonable pay; for this reason, leading a balanced life. On the contrary, conditions were unfavorable when the person is jobless and/or have a mediocre and irregular income not allowing him to lead a stable and balanced life.

\section{Results}

The proportion of early maternity cases at Gecamines Kipushi Hospital was 
42.9\% (Table 1).

The majority of the people investigated on were aged between 16 - 18 years, or $85 \%$. The average age of the mother was $14.7 \pm 2$ years old (Table 2 ).

The table shows that $65 \%$ of the mothers of the newborn babies surveyed were single and $35 \%$ of the mothers were married (Table 3 ).

Social and economic conditions of most mothers were negative, at $68.3 \%$ (Table 4).

Most partners were sellers (25\%), government officials (28\%), ore diggers (16.7\%) and policemen (8.3\%) (Table 5).

Urogenital infections were the major complications of pregnancy (38.3\%) followed by the threat of spontaneous abortion (15\%) and anemia (11.7\%) (Table 6).

By this table, we found that $90 \%$ of pregnancies were singleton and $10 \%$ of twin pregnancies (Table 7).

Through this table, we have noticed that a small proportion of the investigated newborn babies, $18.2 \%$, were born at term while $81.8 \%$ were born prematurely (Table 8).

$95 \% \mathrm{CI}=[1.57-27.2], \mathrm{OR}=6.5, \mathrm{p}=0.005$.

Women with premature rupture of membranes were 6.5 times more likely to deliver prematurely (increased risk with a statistically significant difference, $p=$ 0.005) (Table 9).

Maternal mortality at Gecamines Kipushi Hospital was 6.7\% (Table 10).

All the cases of maternal death were due to post-partum haemorrhages or $100 \%$ (Table 11).

At the first minute, $28.8 \%$ of newborn babies had an Apgar score of less than or equal to 6 (Table 12).

New birth mortality at Gecamines Kipushi Hospital was 7.6\% (Table 13).

This table shows that $60 \%$ of dead newborn babies were premature babies and other $40 \%$ were in severe respiratory distress (Table 14).

Table 1. Frequency of early maternity.

\begin{tabular}{ccc}
\hline Early maternity & Size & $\%$ \\
\hline No & 80 & 57.1 \\
Yes & 60 & 42.9 \\
Total & 140 & 100 \\
\hline
\end{tabular}

Table 2. Distribution of the investigated persons with regard to age.

\begin{tabular}{ccc}
\hline Age of mothers (in years) & Number & $\%$ \\
\hline $13-15$ & 9 & 15 \\
$16-18$ & 51 & 85 \\
Total & 60 & 100 \\
\hline
\end{tabular}


N. M. N. Adelard et al.

Table 3. Distribution of mothers of newborn babies investigated according by their marital status.

\begin{tabular}{ccc}
\hline Marital Status & Size & $\%$ \\
\hline Single & 39 & 65 \\
Married & 21 & 35 \\
Total & 60 & 100 \\
\hline
\end{tabular}

Table 4. Case Distribution according to Social and economic conditions.

\begin{tabular}{ccc}
\hline Social and economic conditions & Size & $\%$ \\
\hline Favorable & 19 & 31.7 \\
Negative & 41 & 68.3 \\
Total & 60 & 100 \\
\hline
\end{tabular}

Table 5. Case Distribution with reference to the occupation of the partner.

\begin{tabular}{ccc}
\hline Occupation & Size & $\%$ \\
\hline Mineral digger (craftsmen miner) & 13 & 16.7 \\
Seller & 15 & 25 \\
Policeman & 5 & 8.3 \\
Government officials & 17 & 28.3 \\
None & 13 & 21.7 \\
Total & 60 & 100 \\
\hline
\end{tabular}

Table 6. Distribution of cases according to pregnancy complications.

\begin{tabular}{ccc}
\hline pregnancy complications & Size & $\%$ \\
\hline Anemic women & 7 & 11.7 \\
Spontaneous abortion threat & 9 & 15 \\
Urogenital infections & 23 & 38.3 \\
None & 21 & 35 \\
Total & 60 & 100 \\
\hline
\end{tabular}

Table 7. Distribution of newborn babies investigated with reference to type of pregnancy.

\begin{tabular}{ccc}
\hline Type of pregnancy & Size & $\%$ \\
\hline Singleton & 54 & 90 \\
Twin & 6 & 10 \\
Total & 60 & 100 \\
\hline
\end{tabular}

Table 8. Distribution of the newborn babies investigated by gestational age at birth.

\begin{tabular}{ccc}
\hline Gestational age (S. A) & Size & $\%$ \\
\hline $28-32$ & 5 & 7.6 \\
$33-36$ & 49 & 74.2 \\
$37-42$ & 12 & 18.2 \\
Total & 66 & 100 \\
\hline
\end{tabular}


Table 9. Distribution of newborn babies according to the risk of premature delivery after rupture of membranes.

\begin{tabular}{cccc}
\hline $\begin{array}{c}\text { Delivery term } \\
\text { membrane condition }\end{array}$ & $\begin{array}{c}\text { Premature } \\
\text { delivery }\end{array}$ & $\begin{array}{c}\text { Full term } \\
\text { delivery }\end{array}$ & Total \\
\hline Premature rupture of the membranes & $9(75 \%)$ & $17(35.5 \%)$ & $26(39.4 \%)$ \\
None & $3(25 \%)$ & $37(68.5 \%)$ & $40(60.6 \%)$ \\
Total & $12(18.2 \%)$ & $54(81.8 \%)$ & $66(100 \%)$ \\
\hline
\end{tabular}

Table 10. Distribution of deliveries with reference to prognosis after delivery.

\begin{tabular}{ccc}
\hline Life expectancy of mothers & Size & $\%$ \\
\hline Living & 56 & 93.3 \\
Death & 4 & 6.7 \\
Total & 60 & 100 \\
\hline
\end{tabular}

Table 11. Distribution of mothers with regard to the causes of death.

\begin{tabular}{ccc}
\hline Causes of mothers' death & Number & $\%$ \\
\hline Haemorrhages of post-partum & 4 & 100 \\
Total & 4 & 100 \\
\hline
\end{tabular}

Table 12. Distribution of newborn babies according to APGAR at first minute.

\begin{tabular}{ccc}
\hline APGAR $\left(1^{\text {st }}\right.$ minute $)$ & Size & $\%$ \\
\hline 6 & 19 & 28.8 \\
$\geq 7$ & 47 & 71.2 \\
Total & 66 & 100 \\
\hline
\end{tabular}

Table 13. Distribution of newborn babies according to life prediction.

\begin{tabular}{ccc}
\hline Life prognosis & Size & \\
\hline Living & 61 & 92.4 \\
Dead & 5 & 7.6 \\
Total & 66 & 100 \\
\hline
\end{tabular}

Table 14. Distribution of newborn babies with regard to neonatal death causes.

\begin{tabular}{ccc}
\hline Neonatal death causes & Number & $\%$ \\
\hline Prematurity & 3 & 60 \\
Severe respiratory distress & 2 & 40 \\
Total & 5 & 100 \\
\hline
\end{tabular}

\section{Discussion}

Early motherhood poses several obstetrical problems and caring for a child when 
one is still a child is not easy [3]. For WHO [4], complications of pregnancy and childbirth are the second leading cause of death among girls aged $15-19$ in the world. Early pregnancy increases the risk for both the mother and the child.

Low- and middle-income countries have high birth rates [4]. In sub-Saharan Africa, more than half of women give birth before the age of 20 [5]. In Senegal, the fertility of adolescent girls is due to the many pressures exerted in the context of the institution of marriage addressed to certain cultural and/or religious rules [6].

In Congo, the rate of early marriage is $40 \%-50 \%$ with $8 \%-15 \%$ of girls having had a child at the age of 15 years [5].

In DR Congo, these adolescent girls, who make up $25 \%$ of all women of childbearing age, account for nearly $14 \%$ of women's total fertility [7].

In our study in Kipushi, early maternity had a frequency of $42.9 \%$. This proportion is higher than that of DR Congo [7] and the world in general [4]. However, it is close to that of Congo-Brazzaville [5]. Among these teenagers in early pregnancy, $65 \%$ were single and $35 \%$ were married. Previous studies have shown the influence of culture, religion [3] [6] and environment [4] [8]. Thus, these pregnancies in adolescence constitute a violent collusion of the virtual adolescent and generational [9]. At this point, the denial of pregnancy becomes a reality [5].

In addition, adverse social and economic conditions (at 68.3\%) justified teenage pregnancies in this study. Although some teenage girls are married (35\%), their husbands have only low-income, monthly occupations $(16.7 \%$ craftsmen miners, $25 \%$ salespeople, $8.3 \%$ policemen, and Government officials at $28.3 \%$ ). Miaflo has also blamed poor social and economic conditions and hard work for early childbearing in sub-Saharan Africa [10].

Early pregnancy increases the risk for both mother and child [4]. Our results showed that $6.7 \%$ of the mothers had died. These mothers experienced threats of spontaneous abortion (15\%), urogenital infections (38.3\%) and anemia (11.7\%). Iloki et al. also mentioned infections and anemia [11]. WHO has classified high-risk pregnancies as those under 16 years of age, for whom medical monitoring is a prerequisite for reducing the risk of maternal and neonatal mortality [9].

The fetal prognosis is fatal at $7.6 \%$ of cases. $28.8 \%$ of children were born with an Apgar score of less than 6. They came from twin pregnancies (10\%) and were born prematurely for more than $81.8 \%$. These premature births $(75 \%)$ were influenced by premature rupture of the membranes $(\mathrm{OR}=6.5, \mathrm{p}=0.005)$.

Previous studies have confirmed our results. Adolescent girls had high perinatal risks, including prematurity [3] [12], with a high mortality rate [4] [11].

We retain that teenage pregnancy remains at high risk [3] [13] [14]. The management of pregnancy and education for the safety of the health and development of her child remain aspects to be deepened in our environment. 


\section{Conclusions}

In urban and rural areas, early maternity was $42.9 \%$. Young girls who experienced early childbearing were mostly single (65\%), with poor social and economic conditions and with $38.3 \%$ urogenital infections, anemia and spontaneous abortion with premature rupture of the membranes, the obstetric outcome was unfavorable at $18.2 \%$. Neonatal mortality was estimated at $7.6 \%$.

Mass awareness campaigns should be organized for young girls on the importance of schooling and on the disadvantages of early childbearing.

\section{References}

[1] Konicheckis, A. (2006) Teenage Pregnancy and Weaving of Adolescent Girls' Early Links. INST-CNRS, 24, 175-188.

[2] Bouchard, D. (2002) Maternity in Adolescence: Obstetric Analysis and Review of the Influence of Culturo-Socio-Economic and Psychological Factors. Journal of $O b$ stetric and Biological Reproductive Gynecology, 30, 944-952.

[3] Anidjar, S. Pregnancy of Teenage Mothers in Morocco. www.Solyanidjar.superforum.fr

[4] WHO (2014) Teen Pregnancy. Aide Memoire, 364. http://www.who.int

[5] WHO (2006) Evolution and Perinatal and Postnatal Delivery Complications with the Mothers Aged Less than 20 Years in Sub-Saharan Africa. http://www.who.int

[6] Kolou, M. (2013) Early Pregnancies in Schools: Causes, Consequences and Approach to Solutions. Senegal.

[7] Kitoga (2008) Etiological Assessment and Complications of Pregnancy before Adulthood in Different Rural Areas in Kinshasa. Journal of Gynecology-Obstetrics and Reproductive Biology, 17, 25.

[8] Skander, B.K., Magdalena, I. and Demetra-Gabriela, S. (2016) When Children Become Parents. Psycho-Social, Medical and Ethical Aspects Related to Maternity among Tunisian Teenagers. Studia Universitatis Babes-Bolyai-Philosophia, 61, 113-122.

[9] Missionnier, S. and Vlachopoulou, X. (2017) Teenage Pregnancy at the Crossroads of Pluralities. Dialogue, 3, 97-110.

[10] Miaffo, S.L. (2008) Risk Factors and Prognosis of Low Birth Weight Cases at the Gyneco-Obstetric and Pediatric Hospital in Yaoundé.

[11] Iloki, L.-H., Itoua, C. and Mbemba Moutounou, M. (2004) Pregnancy and Teenage Birth in Congo-Brazzaville. Journal of Gynecology-Obstetrics and Reproductive Biology, 33, 37-42. https://doi.org/10.1016/S0368-2315(04)96310-7

[12] Bayle, B. (2016) Negations of Pregnancies: A Disorder of Psychic Pregnancy. http://www.cairn.info

[13] Wemaux-Denis, C., et al. (2017) Pregnancy and Delivery of the Adolescent: Is the Obstetric Prognosis More Unfavorable between 13 and 15 Years? Gyneco-Obst Fertility and Senology, 45, 5-8.

[14] Jerome, L. (2010) Teenage Pregnancy. Gynecology and Obstetrics. 